\title{
Article \\ Effect of Inoculation Level on the Impact of the PGPR Azospirillum lipoferum CRT1 on Selected Microbial Functional Groups in the Rhizosphere of Field Maize
}

\author{
Sébastien Renoud ${ }^{1}$, Danis Abrouk ${ }^{1}$ (D), Claire Prigent-Combaret ${ }^{1}$, Florence Wisniewski-Dyé ${ }^{1}$ (D), \\ Laurent Legendre ${ }^{1,2}$, Yvan Moënne-Loccoz ${ }^{1}$ (D) and Daniel Muller ${ }^{1, *(D)}$
}

1 Univ Lyon, Université Claude Bernard Lyon 1, CNRS, INRAe, VetAgro Sup, UMR5557 Ecologie Microbienne, 43 bd du 11 Novembre 1918, F-69622 Villeurbanne, France; seb.renoud@gmail.com (S.R.); danis.abrouk@univ-lyon1.fr (D.A.); claire.prigent-combaret@univ-lyon1.fr (C.P.-C.); Florence.Wisniewski@univ-lyon1.fr (F.W.-D.); laurent.legendre@univ-lyon1.fr (L.L.); yvan.moenne-loccoz@univ-lyon1.fr (Y.M.-L.)

2 Département de Biologie Biochimie, Univ Lyon, Université Jean Monnet, UFR des Sciences et Techniques, F-42000 Saint-Etienne, France

* Correspondence: daniel.muller@univ-lyon1.fr; Tel.: +33-4-72-43-27-14

Citation: Renoud, S.; Abrouk, D.; Prigent-Combaret, $\mathrm{C}$;

Wisniewski-Dyé, F.; Legendre, L.;

Moënne-Loccoz, Y.; Muller, D. Effect of Inoculation Level on the Impact of the PGPR Azospirillum lipoferum CRT1 on Selected Microbial Functional Groups in the Rhizosphere of Field Maize. Microorganisms 2022, 10, 325. https://doi.org/10.3390/ microorganisms10020325 Academic Editor: Diana Di Gioia

Received: 31 December 2021

Accepted: 26 January 2022

Published: 31 January 2022

Publisher's Note: MDPI stays neutral with regard to jurisdictional claims in published maps and institutional affiliations.

Copyright: (C) 2022 by the authors. Licensee MDPI, Basel, Switzerland. This article is an open access article distributed under the terms and conditions of the Creative Commons Attribution (CC BY) license (https:// creativecommons.org/licenses/by/ $4.0 /)$.

\begin{abstract}
The impact of inoculated plant growth-promoting rhizobacteria (PGPR) on its host physiology and nutrition depends on inoculum level. Whether the impact of the inoculated PGPR on the indigenous rhizosphere microbiota also varies with the PGPR inoculum level is unclear. Here, we tested this issue using the PGPR Azospirillum lipoferum CRT1-maize model system, where the initial seed inoculation is known to enhance maize growth and germination, and impacts the maize rhizomicrobiota, including microbial functional groups modulating plant growth. A. lipoferum CRT1 was added to the seeds at standard $\left(10^{5-6}\right.$ cells.seed $\left.^{-1}\right)$ or reduced $\left(10^{4-5}\right.$ cells.seed $\left.^{-1}\right)$ inoculation levels, in three fields. The effect of the two PGPR formulations was assessed on maize growth and on the nifH (nitrogen fixation), acdS (ACC deaminase activity) and phlD (2,4-diacetylphloroglucinol production) microbial functional groups. The size of the three functional groups was monitored by qPCR at the six-leaf stage and the flowering stage, and the diversity of the nifH and acdS functional groups (as well as the bacterial community) were estimated by MiSeq metabarcoding at the six-leaf stage. The results showed that the benefits of the reduced inoculant formulation were significant in two out of three fields, but different (often lower) than those of the standard formulation. The effects of formulations on the size of the three functional groups differed, and depended on field site and functional group. The reduced formulation had an impact on the diversity of nifH and acdS groups at one site, whereas the standard formulation had an impact at the two other sites. Inoculation significantly impacted the total bacterial community in the three fields, but only with the reduced formulation. In conclusion, the reduced inoculant formulation impacted the indigenous rhizosphere microbiota differently, but not less efficiently, than the standard formulation.
\end{abstract}

Keywords: functional community; diazotrophs; nitrogen fixers; ACC deaminase producers

\section{Introduction}

The inoculation of plants with beneficial microorganisms such as Plant-GrowthPromoting Rhizobacteria (PGPR) to enhance crop productivity is an over one-hundred-yearold farming technique [1,2]. Indeed, PGPR (encompassing a diversity of bacterial taxa [3]) can benefit plant growth by several mechanisms, such as (i) modulating plant hormonal balance via the production of auxins, gibberellins, abscisic acid or 1-aminocyclopropane1-carboxylate (ACC) deaminase, resulting in a stimulation of root-system development and soil prospection by roots, and (ii) the improvement of plant nutrition by phosphate solubilisation or atmospheric nitrogen fixation [4-8]. In Latin America, South-East Asia 
and Africa, inoculated seeds are sown at a large scale, with millions of hectares of Fabaceae (e.g., soybean or bean) and Poaceae (e.g., maize, sorghum or wheat) inoculated by PGPR belonging mainly to the genera Bacillus, Paenibacillus, Pseudomonas or Azospirillum [2,9-12]. In the context of ecological awareness in agronomy, biofertilisation with microorganisms constitutes an attractive alternative to chemical inputs, which are polluting and decrease soil fertility [13-16]. Various studies reported that PGPR inoculant functioning under field conditions is impacted by soil type and plant genotype, as well as the PGPR strains used $[2,9,10,17-21]$.

Unlike under greenhouse conditions, field-inoculation of phytobeneficial microorganisms is associated with variable levels of success. Consequently, the development of inoculant formulation (i.e., the combination of the bacterial strain with a carrier) that provides more suitable micro-environmental conditions can be useful to improve inoculant performance [2,22]. The inoculant formulation should stimulate the optimum establishment, and functioning, of the inoculant, so as to maximize its effects on the plant. A major objective of the formulation is to deliver a number of inoculant cells sufficient to induce plant stimulation $[1,22,23]$. Indeed, the inoculum dose has been described as an important factor to observe a beneficial effect on the plant. Generally, the number of inoculant cells necessary should be in the order of $10^{6}$ to $10^{7}$ per seeds $[24,25]$ and, in most studied cases, the correlation between inoculum density and phytostimulation effectiveness is tight [26-28].

Azospirillum lipoferum CRT1 is a natural PGPR isolate that is commercially used on maize to stimulate plant growth, and field yield, with a peat-based seed-coating formulation providing $10^{5-6}$ CFU of bacteria per seed [29,30]. Nevertheless, phytostimulation can also be achieved at lower inoculation levels, and we evidenced positive effects of $A$. lipoferum CRT1 on maize physiology with only $10^{4-5}$ inoculant cells per seed [20,21,31]. In addition to direct effects on maize physiology [29], inoculation of maize seeds with A. lipoferum CRT1 affects the bacterial community of the rhizosphere [21,32]; this includes specific microbial functional groups important for plant growth [21], such as diazotrophs (nitrogen fixation), ACC deaminase producers (regulators of ethylene metabolism in roots), and producers of 2,4-diacetylphloroglucinol, a root-branching signal with auxinic effects [33]. Therefore, it is likely that phytostimulation by this PGPR involves a combination of direct effects on the plants, as well as indirect effects on the indigenous rhizosphere microbial community. In light of this background, the impact of low inoculant doses should also be evaluated on these indigenous microbial phytostimulators. In particular, we hypothesize that reduced inoculum levels affect, albeit to a lesser efficiency, microbial functional groups in parallel to their effects on maize physiology.

The objective of this work was to assess the effect of a reduced inoculum level $\left(10^{4-5}\right.$ cells.seed $^{-1}$; formulation F1) of $A$. lipoferum CRT1 on its host physiology and rhizosphere microbial communities, in comparison with a standard inoculum level $\left(10^{5-6}\right.$ cells.seed $^{-1}$; formulation F2) under agronomic conditions. These maize inoculation experiments were carried out in parallel at three different field sites; additionally, results obtained with the F1 formulation on maize photosynthesis efficiency, metabolome, growth and yield have been previously reported [20], along with findings on nitrifying and denitrifying communities in bulk soil [31], as well as diazotroph communities, ACC deaminase producer communities and 2,4-diacetylphloroglucinol producer communities in the rhizosphere [21]. However, formulation F1 data-enabling to compare the two inoculation levels has not been reported, and this was the focus of this study. Thus, the influence of the inoculation level of A. lipoferum CRT1 on the inoculant effect on shoot and root development was investigated. In addition, to consider the possibility of indirect plant-beneficial effects, we also monitored the indigenous rhizosphere community via the size and/or diversity of the diazotrophs, ACC deaminase producers and 2,4-diacetylphloroglucinol producers, and the assessment of the diversity of the overall bacterial community. 


\section{Results}

\subsection{Inoculum Survival}

Quantitative PCR analysis of A. lipoferum CRT1 DNA on maize rhizosphere soil samples at the six-leaf and flowering stages did not yield any signal, indicating that the inoculant $A$. lipoferum CRT1 was under the detection threshold (i.e., below $4.0 \times 10^{3}$ cell equivalents per $\mathrm{g}$ of rhizosphere soil) in the three field trials, irrespective of the formulation. This also indicates that indigenous Azospirillum strains closely related to the inoculant were not present in the three field sites.

\subsection{Effects of Inoculum Level on Maize Development}

In the absence of inoculation, the F1 seed mock formulation resulted, at the six-leaf stage, in a $48 \%$ decrease in the number of maize roots (at site L), a $10 \%$ increase in leaf length and a 10\% increase in average root diameter (at site FC), a 4\% decrease in total root length (at site FC), and a 9\% increase in leaf width (at site C) in comparison with the F2 mock (control) treatment (Table 1).

At site L, seed inoculation with A. lipoferum CRT1 resulted in significantly higher shoot biomass ( $+26 \%$ with F1 vs. $+29 \%$ with F2), leaf width $(+10 \%$ with F1 only) or leaf length $(+10 \%$ with F2 only), stem diameter $(+11 \%$ with F1 vs. $+13 \%$ with F2), root biomass $(+20 \%$ with F1 only), total root length $(+43 \%$ with F1 vs. $+47 \%$ with F2), total root surface $(+42 \%$ with F1 vs. $24 \%$ with F2) and number of roots (+91\% with F1 vs. $+160 \%$ with F2), but lower average root diameter ( $-14 \%$ with F2 only), in comparison with the corresponding non-inoculated mock controls (Table 1). At site FC, inoculation caused an $18 \%$ decrease in root biomass with F1 only (compared with the F1 control), whereas with F2 it led to higher shoot biomass $(+26 \%)$, leaf length $(+10 \%)$, stem diameter $(+12 \%)$ and number of roots $(+29 \%)$ in comparison with the F2 non-inoculated control (Table 1). At site C, the use of CRT1 resulted in higher shoot biomass (+15\% with F1 vs. $+24 \%$ with F2), leaf length ( $+9 \%$ with F2 only), leaf width ( $+12 \%$ with F2 only) and stem diameter ( $+10 \%$ with F2 only), but lower average root diameter ( $-9 \%$ with F1 vs. $-10 \%$ with F2), compared with the corresponding non-inoculated mock controls (Table 1).

\subsection{Effects of Inoculum Level on Numbers of nifH, acdS and phlD Rhizobacteria}

In the absence of the inoculant bacterium, seed mock-coating had an effect on the size of the three functional groups under scrutiny at certain field sites and sampling dates. At the six-leaves stage, the number of rhizosphere nifH bacteria in the F1 control samples was lower in FC ( $-0.5 \mathrm{log})$ but higher in C (+0.4 log) than in the F2 control samples. At the flowering stage, the $\mathrm{F} 1$ control rhizosphere soil samples had a reduced nifH group in $\mathrm{L}$ $(-0.4 \log )$ and FC ( $-0.3 \log )$, acd S group in L ( $-0.3 \log ), \mathrm{FC}(-0.5 \log )$ and $\mathrm{C}(-0.2 \log )$, and phlD group in FC ( $-0.7 \mathrm{log})$, in comparison with the F2 control (Figure 1$)$.

At the six-leaf stage, seed inoculation with A. lipoferum CRT1 resulted in a significantly different size for the nifH group at sites L (+0.7 log with F2 only), FC ( $-0.5 \log$ with F2 only) and C ( $-0.3 \log$ with F1 only) and for the acdS group in C (+0.3 log with F2 only), but not for the phlD group (Figure 1). At the flowering stage, A. lipoferum CRT1 inoculation increased the size of the nifH group in FC $(+0.7 \log$ with F1 vs. $+0.3 \log$ with F2) and C $(+0.5 \log$ with F1 vs. $+0.8 \log$ with F2), of the acdS group in $\mathrm{L}(+0.2 \log$ with F1 only), FC $(+0.8 \log$ with F1 vs. $+0.3 \log$ with F2) and C (+0.6 log with F2 only), and of the phlD group in FC (+0.9 log with F1 only). 
Table 1. Effect of inoculum level of Azospirillum lipoferum CRT1 on root and shoot parameters of maize grown at the three fields sites L (Chatonnay), FC (Sérézin-laTour) and C (Saint Savin). Formulation F1 corresponds to the peat matrix used to coat seeds with low inoculant concentration, and the corresponding data in this table originate from [21]. In formulation F2, A. lipoferum CRT1 was used at higher inoculant concentration. Stem diameter was measured at root collar level and foliar morphology on leaf number five. At each field site, statistical differences between the four treatments are indicated by letters a-c (ANOVA and Fischer's LSD tests, $p<0.05)$

\begin{tabular}{|c|c|c|c|c|c|c|c|c|c|c|c|c|}
\hline \multirow{3}{*}{ Plant Parameters } & \multicolumn{4}{|c|}{ Site L } & \multicolumn{4}{|c|}{ Site FC } & \multicolumn{4}{|c|}{ Site C } \\
\hline & \multicolumn{2}{|c|}{ Control } & \multicolumn{2}{|c|}{ Inoculated } & \multicolumn{2}{|c|}{ Control } & \multicolumn{2}{|c|}{ Inoculated } & \multicolumn{2}{|c|}{ Control } & \multicolumn{2}{|c|}{ Inoculated } \\
\hline & F1 & F2 & F1 & F2 & F1 & F2 & F1 & F2 & F1 & F2 & F1 & F2 \\
\hline Shoot biomass (g plant ${ }^{-1}$ ) & $0.34 \pm 0.07$ (b) & $0.34 \pm 0.07$ (b) & $0.43 \pm 0.11$ (a) & $0.44 \pm 0.1$ (a) & $0.52 \pm 0.14(\mathrm{bc})$ & $0.50 \pm 0.12$ (c) & $0.59 \pm 0.17(\mathrm{ab})$ & $0.63 \pm 0.15$ (a) & $0.34 \pm 0.08$ (b) & $0.33 \pm 0.07$ (b) & $0.39 \pm 0.07$ (a) & $0.41 \pm 0.08$ (a) \\
\hline $\begin{array}{l}\text { Shoot biomasss (g plant } \\
\text { Leaf length (cm plant }{ }^{-1} \text { ) }\end{array}$ & $\begin{array}{l}.34 \pm 0.07(\text { (b) } \\
13.1 \pm 1.6(\mathrm{~b})\end{array}$ & $\begin{array}{l}.34 \pm 0.07(\text { (b) } \\
13.8 \pm 1.6(b)\end{array}$ & $\begin{array}{l}0.43 \pm 0.11 \text { (a) } \\
14.0 \pm 1.9(\mathrm{~b})\end{array}$ & $\begin{array}{l}0.44 \pm 0.1 \text { (a) } \\
15.2 \pm 1.7 \text { (a) }\end{array}$ & $\begin{array}{l}0.52 \pm 0.14(\mathrm{bc}) \\
20.7 \pm 1.7(\mathrm{a})\end{array}$ & $\begin{array}{l}0.50 \pm 0.12(\mathrm{c}) \\
18.8 \pm 1.9(\mathrm{~b})\end{array}$ & $\begin{array}{l}.09 \pm 0.17(\mathrm{ab}) \\
19.8 \pm 2.1(\mathrm{ab})\end{array}$ & $\begin{array}{l}0.63 \pm 0.15(\mathrm{a}) \\
20.6 \pm 2.1 \text { (a) }\end{array}$ & $\begin{array}{l}.3 .54 \pm .08(\mathrm{~g}) \\
17.9 \pm 2.4(\mathrm{ab})\end{array}$ & $\begin{array}{l}0.33 \pm 0.0 \text { (b) } \\
16.8 \pm 1.7(\mathrm{~b})\end{array}$ & $\begin{array}{l}.3990 .07(\mathrm{a}) \\
17.2 \pm 1.8(\mathrm{ab})\end{array}$ & $\begin{array}{l}0.41 \pm 0.00 \text { (a) } \\
18.3 \pm 2.3 \text { (a) }\end{array}$ \\
\hline $\begin{array}{l}\text { Lear lenggth (cm plant }-) \\
\text { Leaf width }\left(\mathrm{cm}_{\text {plant }}^{-1}\right)\end{array}$ & $\begin{array}{l}1.53 \pm 0.15(\mathrm{~b}) \\
1.53\end{array}$ & $\begin{array}{l}1.8 \pm 1.6(\mathrm{~d}) \\
1.61 \pm 0.13(\mathrm{ab})\end{array}$ & $\begin{array}{l}1.0 \pm 1.9(\mathrm{pl}) \\
1.68 \pm 0.12 \text { (a) }\end{array}$ & $\begin{array}{l}1.59 \pm 0.17 \text { (b) } \\
1.59\end{array}$ & $1.61 \pm 0.11$ (a) & $\begin{array}{l}1.8 \pm 1.9 \text { (1) } \\
1.59 \pm 0.12 \text { (a) }\end{array}$ & $\begin{array}{l}1.8 \pm 2.1 \mathrm{ab}) \\
1.64 \pm 0.14(\mathrm{a})\end{array}$ & $\begin{array}{l}20.6 \pm 2.1 \text { (a) } \\
1.65 \pm 0.14 \text { (a) }\end{array}$ & $\begin{array}{l}1.71 \pm 0.13(\mathrm{a}) \\
\text { (a) }\end{array}$ & $\begin{array}{l}1.8 \pm 1.1(\mathrm{~b}) \\
1.57 \pm 0.11(\mathrm{~b})\end{array}$ & $1.71 \pm 0.17(\mathrm{a})$ & $\begin{array}{l}1.3 \pm 2.3 \text { (a) } \\
1.76 \pm 0.14 \text { (a) }\end{array}$ \\
\hline $\begin{array}{l}\text { Leat width (cm plant }) \\
\text { Stem diameter }(\mathrm{mm})\end{array}$ & $\begin{array}{l}\text { l. } \\
6.87 \pm 0.73 \text { (b) }\end{array}$ & $\begin{array}{l}1.01 \pm 0.13(\mathrm{dob}) \\
6.95 \pm 0.72(\mathrm{~b})\end{array}$ & $7.63 \pm 0.78$ (a) & $\begin{array}{l}1.13 \pm 0.17(\mathrm{l}) \\
7.82 \pm 0.89 \text { (a) }\end{array}$ & $7.74 \pm 1.07$ (b) & $7.55 \pm 1.07$ (b) & $\begin{array}{l}1.04 \pm 0.14(\mathrm{a}) \\
8.04 \pm 0.99(\mathrm{ab})\end{array}$ & $\begin{array}{l}1.03 \pm 0.14 \text { (a) } \\
8.48 \pm 0.94 \text { (a) }\end{array}$ & $7.24 \pm 0.60(\mathrm{ab})$ & $6.83 \pm 0.81$ (b) & $\begin{array}{l}1.11 \pm 0.17(\mathrm{a}) \\
7.06 \pm 0.84(\mathrm{ab})\end{array}$ & $\begin{array}{l}1.16 \pm 0.14 \text { (a) } \\
7.52 \pm 0.79 \text { (a) }\end{array}$ \\
\hline Root biomass (g plant ${ }^{-1}$ ) & $0.20 \pm 0.05$ (b) & $0.23 \pm 0.05(\mathrm{ab})$ & $0.24 \pm 0.05$ (a) & $0.23 \pm 0.05(\mathrm{ab})$ & $0.28 \pm 0.05$ (a) & $0.26 \pm 0.04(\mathrm{ab})$ & $0.23 \pm 0.05(\mathrm{~b})$ & $0.24 \pm 0.05(\mathrm{~b})$ & $0.27 \pm 0.05$ (a) & $0.24 \pm 0.06$ (a) & $0.25 \pm 0.05$ (a) & $0.25 \pm 0.05$ (a) \\
\hline Total root length (cm plant ${ }^{-1}$ ) & $212 \pm 60$ (b) & $225 \pm 56$ (b) & $302 \pm 86$ (a) & $330 \pm 107$ (a) & $418 \pm 109$ (b) & $498 \pm 90$ (a) & $441 \pm 90(\mathrm{ab})$ & $461 \pm 65(\mathrm{ab})$ & $323 \pm 86$ (a) & $280 \pm 66$ (a) & $321 \pm 61$ (a) & $278 \pm 68$ (a) \\
\hline Total root surfaces $\left(\mathrm{cm}^{2}\right.$ plant $^{-1}$ ) & $52 \pm 12$ (b) & $58 \pm 13$ (b) & $73 \pm 20$ (a) & $72 \pm 16$ (a) & $115 \pm 29$ (a) & $124 \pm 20(\mathrm{a})$ & $116 \pm 28$ (a) & $121 \pm 22$ (a) & $90 \pm 24$ (a) & $79 \pm 21(\mathrm{ab})$ & $82 \pm 17(a b)$ & $71 \pm 19$ (b) \\
\hline $\begin{array}{l}\text { Average root diameter }(\mathrm{mm}) \\
\text { Number of foots }\end{array}$ & $\begin{array}{l}0.79 \pm 0.13 \text { (a) } \\
413 \pm \pm 120 \text { (c) }\end{array}$ & $\begin{array}{l}0.83 \pm 0.10 \text { (a) } \\
793 \pm 373(\mathrm{~b})\end{array}$ & $\begin{array}{l}0.78 \pm 0.10(\mathrm{ab}) \\
789 \pm 469(\mathrm{~b})\end{array}$ & $\begin{array}{l}0.71 \pm 0.10 \text { (b) } \\
2057 \pm 1192(\mathrm{a})\end{array}$ & $\begin{array}{l}0.88 \pm 0.08 \text { (a) } \\
569 \pm 87 \text { (b) }\end{array}$ & $\begin{array}{l}0.80 \pm 0.08(\mathrm{~b}) \\
595 \pm 114(\mathrm{~b})\end{array}$ & $\begin{array}{l}0.83 \pm 0.08(\mathrm{ab}) \\
671 \pm 250 \mathrm{ab})\end{array}$ & $\begin{array}{l}0.83 \pm 0.07(\mathrm{ab}) \\
768 \pm 27 \text { (a) }\end{array}$ & $\begin{array}{l}0.89 \pm 0.07 \text { (a) } \\
804 \pm 536 \text { (a) }\end{array}$ & $\begin{array}{l}0.89 \pm 0.09(\mathrm{a}) \\
499 \pm 213(\mathrm{ab})\end{array}$ & $\begin{array}{l}0.81 \pm 0.08 \text { (b) } \\
497 \pm \pm 139(\mathrm{a})\end{array}$ & $\begin{array}{l}0.81 \pm 0.09(\mathrm{~b}) \\
390 \pm 1122(\mathrm{~b})\end{array}$ \\
\hline
\end{tabular}


A

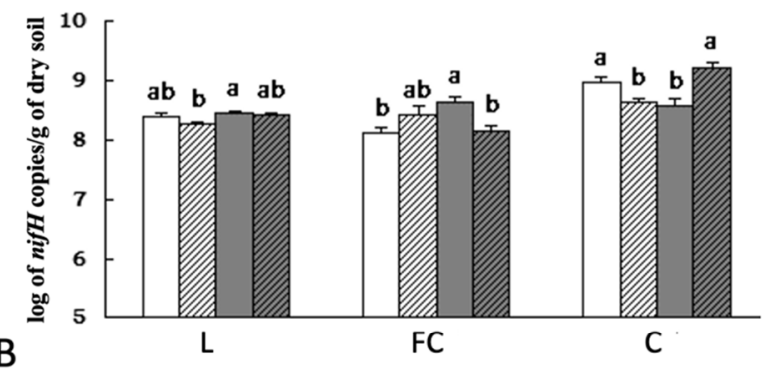

B

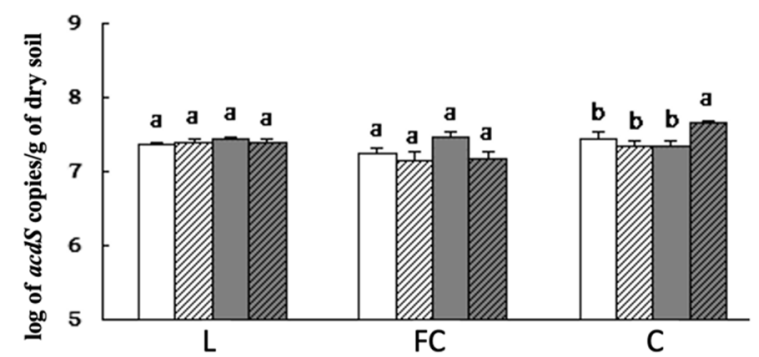

C

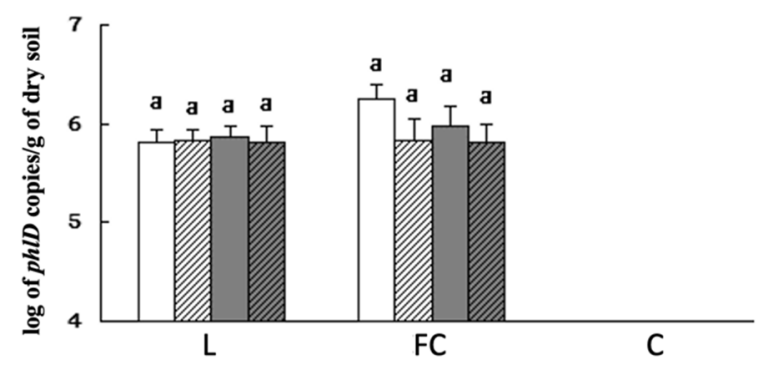

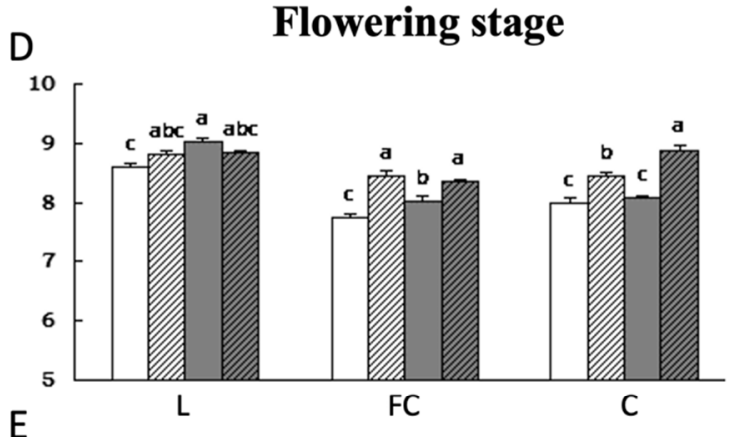

$\mathrm{E}$

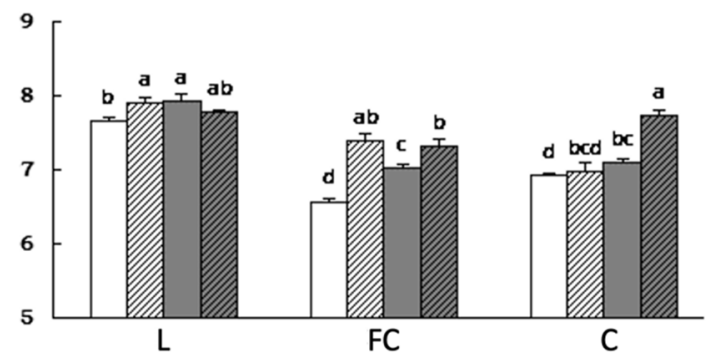

$\mathrm{F}$

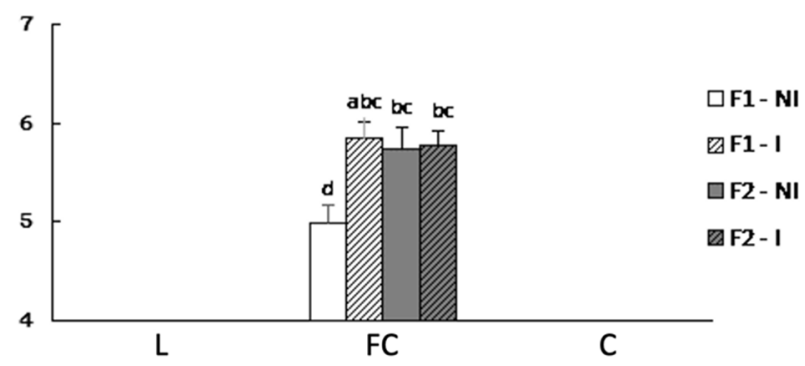

Figure 1. Effect of inoculation level of A. lipoferum CRT1 on the size of nifH $(\mathbf{A}, \mathbf{D})$, acdS $(\mathbf{B}, \mathbf{E})$ and phlD $(\mathbf{C}, \mathbf{F})$ functional groups at two sampling times of maize in three fields. L, FC and C correspond to the three sites studied. Data are shown in $\log$ base 10 , with standard errors $(n=20)$. F1 corresponds to the peat matrix used to coat seeds with low inoculant concentration, and the data originate from [21]. In F2, A. lipoferum CRT1 was used at higher inoculant concentration. NI and I correspond, respectively, to non-inoculated and inoculated conditions. In $\mathrm{C}$ and $\mathrm{F}$, some of the samples were below the detection threshold $\left(3.2 \times 10^{3} \mathrm{phlD}\right.$ copies per gram of lyophilized soil). At each field site, statistical differences between the four treatments are indicated by letters a-d (ANOVA and Fischer's LSD tests, $p<0.05)$.

\subsection{Effects of Inoculum Level on nifH and acdS Diversity of Maize Rhizosphere}

NMDS evidenced that the main differences in the nifH, acdS and rrs datasets of the six-leaf-maize rhizosphere soil were due to field site peculiarities (Figures S7, S8 and S9, respectively). To unmask the overriding effects of field conditions, the impact of inoculation was assessed by BCA.

First, we compared the two treatments with non-bacterized formulations. BCA on the nifH group at sites $\mathrm{L}, \mathrm{FC}$ and $\mathrm{C}$ revealed no difference $(p>0.05)$ in taxa composition (Figure 2). For the acdS group, there was no difference at sites $\mathrm{L}(p=0.29$ for axis $X$ and 0.08 for axis $Y$ ) and FC ( $p=0.60$ for axis $X$ and 0.18 for axis $Y)$, whereas at $C$, the F1 and F2 control samples differed along the ordinate axis ( $p=0.004 ; 24 \%$ of betweenclass variability), especially for the genera Brevibacterium, Micromonospora, Lechevalieria, Phycicoccus, Rhodococcus and Mycobacterium (genera most commonly associated with the non-inoculated formulation F1) and Azorhizobium, Mesorhizobium, Meiothermus, Microvirga, Labrenzia, and Nesterenkonia (genera most commonly associated with the non-inoculated formulation F2) (Figure 3). 


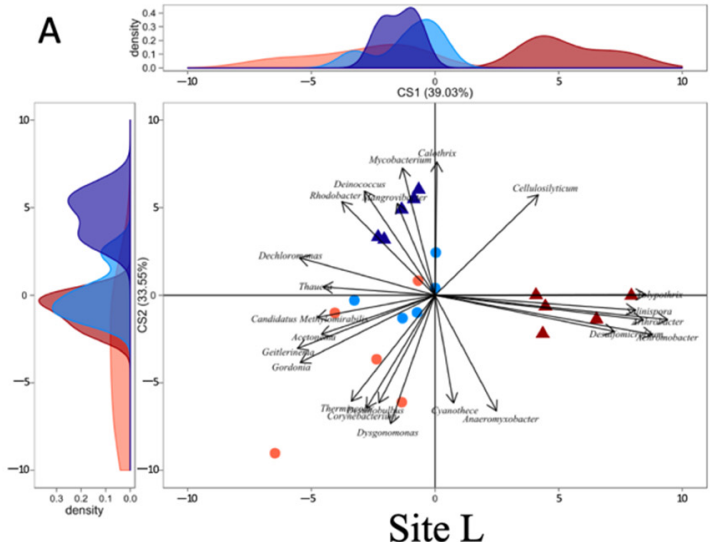

Site L

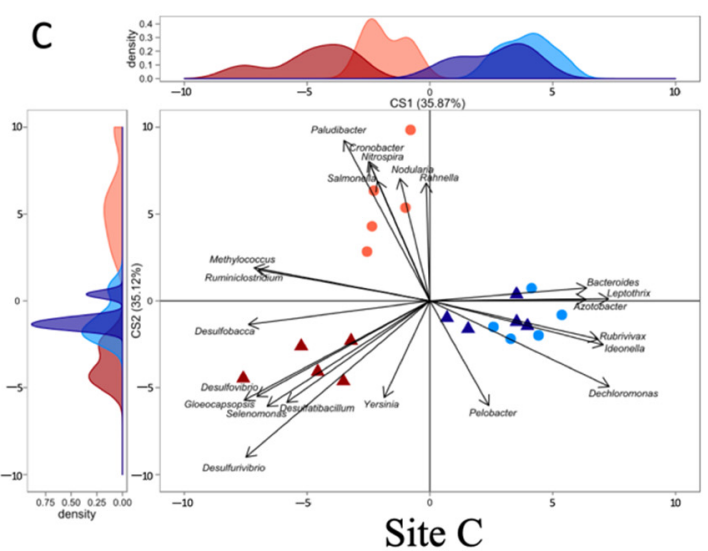

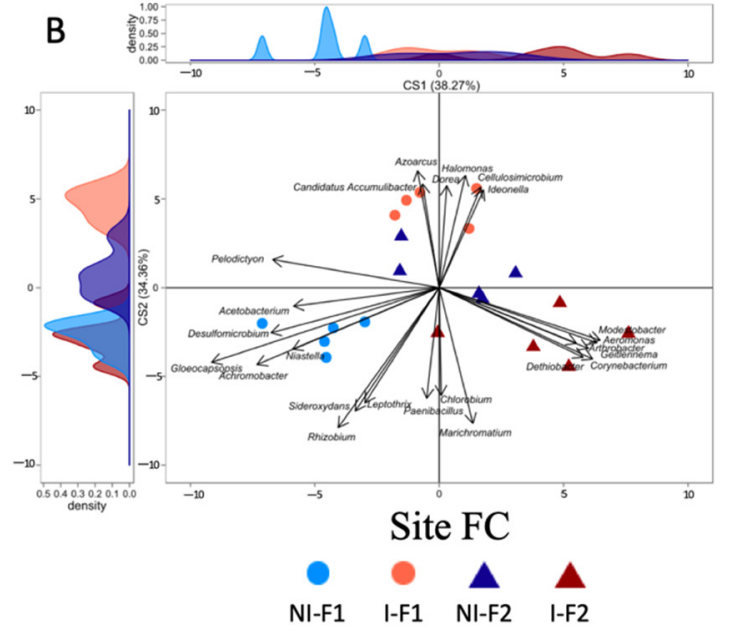

Figure 2. Effect of inoculation level of A. lipoferum CRT1 on the composition of the diazotroph community (nifH) as indicated by between-class analyses (BCA) studied at three field sites L (A), FC (B), and C (C). F1 (circles) corresponds to the peat matrix used to coat seeds with low inoculant concentration, using data originating from [21], and in F2 (triangles), A. lipoferum CRT1 was used at higher inoculant concentration. NI (blue) and I (reddish) correspond, respectively, to non-inoculated and inoculated conditions. Curves on top and left represent, respectively, the sample distribution on abscissa and ordinate axes. Vectors on plot represent the bacterial genera contributing the most to sample distribution.

Second, we compared the nifH group in the rhizosphere soil of non-inoculated and A. lipoferum CRT1-inoculated maize (Figure 2). Based on the BCA of nifH data, the effect of bacterial inoculation at site $\mathrm{L}$ was not significant with $\mathrm{F} 1$ ( $p=0.54$ for axis $\mathrm{X}$ and 0.54 for axis Y) but was significant with F2 along the abscissa axis ( $p=0.004 ; 39 \%$ of between-class variability), where the most discriminant genera were Geitlerinema, Dechloromonas, Gordonia, Candidatus Methylomirabilis, Acetonema and Thauera (most commonly associated with non-inoculated maize) and Nostoc, Achromobactin, Tolypothrix, Arthrobacter, Salinispora and Desulfomicrobium (genera most commonly associated with inoculated maize); bacterial inoculation was also significant with F2 along the ordinate axis ( $p=0.004 ; 34 \%$ of between-class variability), where the most discriminant genera were Calothrix, Mycobacterium, Deinococcus, Cellulosilyticum, Rhodobacter and Mangrovibacter (most commonly associated with non-inoculated maize) and Dysgonomonas, Anaeromyxobacter, Corynebacterium, Cyanothece, Desulfobulbus and Thermincola (genera most commonly associated with inoculated maize). At FC, inoculation had an effect with F1 along the ordinate axis $(p=0.007 ; 34 \%$ of betweenclass variability), with Rhizobium, Marichromatium, Sideroxydans, Leptothrix, Paenibacillus and Chlorobium, most commonly associated with non-inoculated maize, and Azoarcus, Halomonas, Candidatus Accumulibacter, Dorea, Cellulosimicrobium and Ideonella genera most commonly associated with inoculated maize, but not with F2 ( $p=0.54$ for axis $\mathrm{X}$ and 0.14 for axis $\mathrm{Y}$ ). At site $\mathrm{C}$, inoculation had no effect with $\mathrm{F} 1$ ( $p=0.09$ for axis $\mathrm{X}$ and 0.14 for axis 
Y), but F2 samples differed from mock samples along the abscissa axis $(p=0.001 ; 36 \%$ of between-class variability). The most discriminant genera were Dechloromonas, Leptothrix, Ideonella, Rubrivivax, Bacteroides and Azotobacter (genera most commonly associated with non-inoculated maize) and Gloeocapsopsis, Desulfurivibrio, Desulfobacca, Methylococcus, Desulfovibrio and Ruminiclostridium (genera most commonly associated with inoculated maize).

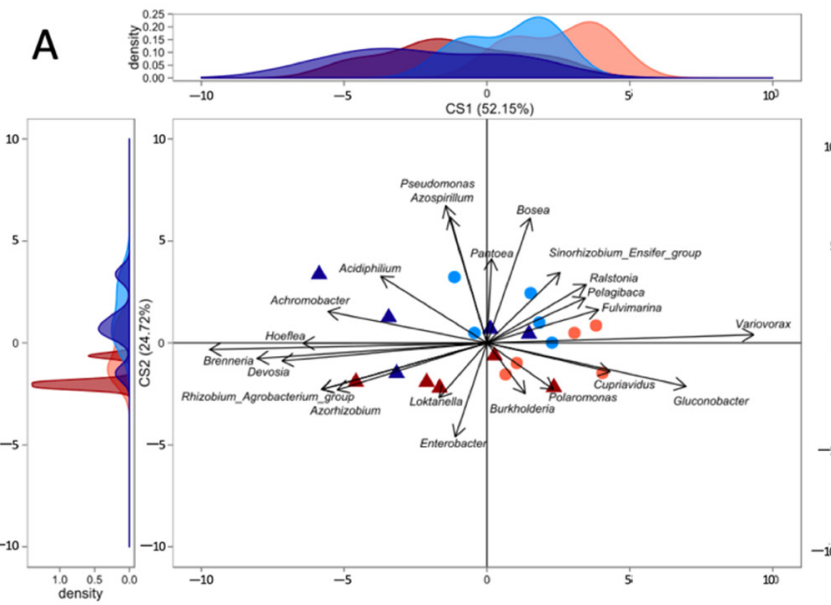

Site L

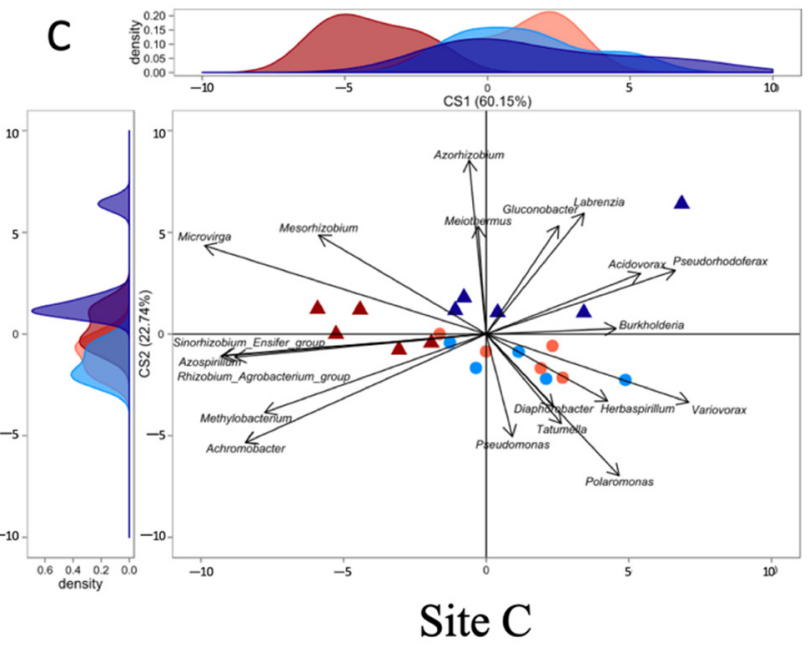

B
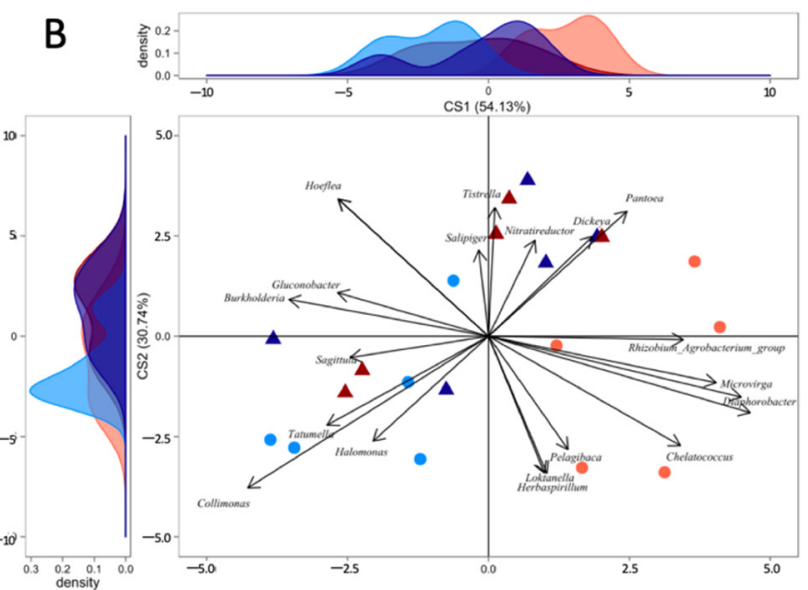

Site FC

NI-F1 I-F1 NI-F2 I-F2

Figure 3. Effect of inoculation level of A. lipoferum CRT1 on the composition of the ACC deaminase producers $(a c d S)$ as indicated by between-class analyses (BCA) studied at three field sites L (A), FC (B), and C (C). F1 (circles) corresponds to the peat matrix used to coat seeds with low inoculant concentration, using data originating from [21], and in F2 (triangles), A. lipoferum CRT1 was used at higher inoculant concentration. NI (blue) and I (reddish) correspond, respectively, to non-inoculated and inoculated conditions. Curves on top and left represent, respectively, the sample distribution on abscissa and ordinate axes. Vectors on plot represent the bacterial genera contributing the most to sample distribution.

Third, we assessed the $a c d S$ group in non-inoculated and inoculated maize rhizosphere soil samples (Figure 3). Based on the BCA of acdS data, there was no effect of inoculation at site L with F1 ( $p=0.90$ for axis $X$ and 0.07 for axis $Y$ ), but there was a difference with F2 along the ordinate axis ( $p=0.038 ; 24 \%$ of between-class variability). The most discriminant taxa were Bradyrhizobium, Chelatococcus, Nesterenkonia, Herbaspirillum, Halomonas and Pelagibaca, most commonly associated with non-inoculated maize, and Nocardia, Collimonas, Gluconobacter, Komagataeibacter and Diaphorobacter, most commonly associated with inocu- 
lated maize. At FC, F1 inoculation had an effect along the abscissa axis ( $p=0.017 ; 53 \%$ of between-class variability), and the most discriminant genera were Collimonas, Nesterenkonia, Burkholderia, Tatumella, Pseudonocardia and Phycicoccus (genera most commonly associated with non-inoculated maize), and Tetrasphaera, Modestobacter, Serinicoccus, Roseovarius, Mesorhizobium and Actinoplanes (genera most commonly associated with inoculated maize), but no significant difference was observed between non-inoculated and inoculated maize with F2. At $\mathrm{C}$, the effect of inoculation was not significant with F1 ( $p=0.99$ for axis $\mathrm{X}$ and 0.85 for axis $\mathrm{Y}$ ) but was significant with F2 along the abscissa axis ( $p=0.030 ; 55 \%$ of between-class variability), and the most discriminant genera were Starkeya, Streptomyces, Achromobacter, Rhizobium/Agrobacterium, Sinorhizobium/Ensifer and Microvirga (genera most commonly associated with non-inoculated maize), and Variovorax, Pseudorhodoferax, Acidovorax and Methylibium (genera most commonly associated with inoculated maize).

In summary, seed inoculation with A. lipoferum CRT1 resulted in significantly different compositions of the nifH and acdS groups at each field site, but this depended on the inoculation level. For both functional groups, the bacterial genera contributing most to the distinction between inoculated and uninoculated maize samples were different between fields. Moreover, within a field, their individual contribution depended on the level of CRT1 inoculation, indicating field-specific effects as well as formulation-specific effects on native rhizosphere bacteria in these functional groups.

2.5. Effects of Inoculum Level on the Genus Composition of the nifH and acdS Groups within the Maize Rhizosphere

Further insight into the effects of CRT1 inoculum level on the nifH and acdS functional groups were sought by considering the 20 most prevalent genera within these groups, even though differences in their relative abundances were not significant at $p<0.05$. Among the diazotrophs (Figure S4), there were trends for Burkholderia, Paenibacillus, Clostridum (at sites L and FC), Desulfovibrio (at sites FC and C), Azospirillum, Bradyrhizobium, Skermanella (at site FC), Azoarcus, Cellulosilyticum, Paludibacter and Ruminiclostridium (at site L) to be more prevalent in F1 inoculated maize. There were also trends for Geobacter (at sites L and FC), Bradyrhizobium (at sites C and L), Paenibacillus, Pelosinus, Pseudomonas (at sites C), Dechloromonas, Desulfovibrio, Rhizobium, Skermanella (at sites L) and Azoarcus (at site FC) to be more prevalent in the rhizophere of F2-inoculated maize than in F1-inoculated maize.

Among the ACC deaminase producers, there were trends for Methylibium, Polaromonas (at sites FC and C), Bradyrhizobium (site FC), Pseudomonas and Variovorax (site C) to be more prevalent after maize F1 inoculation (Figure S5). In F2-inoculated maize rhizosphere samples, there were trends for Burkholderia (at the three sites), Rhizobium (at sites C and L), Pseudomonas, Variovorax (site FC), Bradyrhizobium and Mesorhizobium (site C) to be more prevalent. Thus, for both functional groups, contrasting trends were observed for the majority of these genera as a function of field site, but also of inoculant formulation.

\subsection{Effects of Inoculum Level on the Total Bacterial Diversity of Maize Rhizosphere}

First, we compared the F1 and F2 non-inoculated control treatments on the basis of the taxonomic composition of the rhizosphere bacterial communities, using the BCA (Figure 4) of Illumina MiSeq sequencing of $16 \mathrm{~S}$ rRNA genes ( $r r s)$. At site $\mathrm{L}$, the controls differed along the abscissa axis ( $p=0.044 ; 38 \%$ of between-class variability), with Caloramator, Pelosinus, Fodinicola, Hansschlegelia, Alkalilimnicola and Desulfofrigus most commonly associated with the F1 mock treatment, and Pseudoclavibacter, Frigoribacterium, Arcobacter, Smithella, Cellulosimicrobium and Caedibacter most commonly associated with the F2 mock treatment. The effect of formulation type was not significant at sites FC in the absence of bacterial inoculant ( $p=0.40$ for axis $X$ and 0.10 for axis $Y$ ) and $C(p=0.44$ for axis $X$ and 0.67 for axis $Y$ ). 


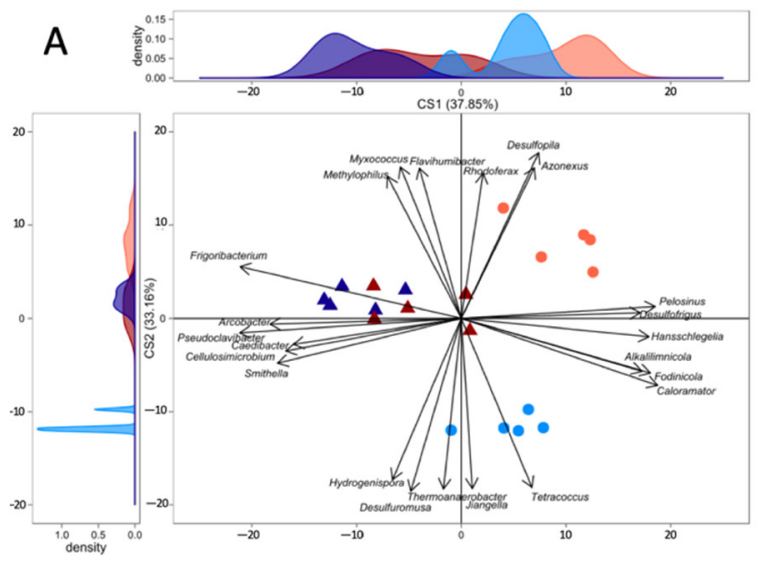

Site L

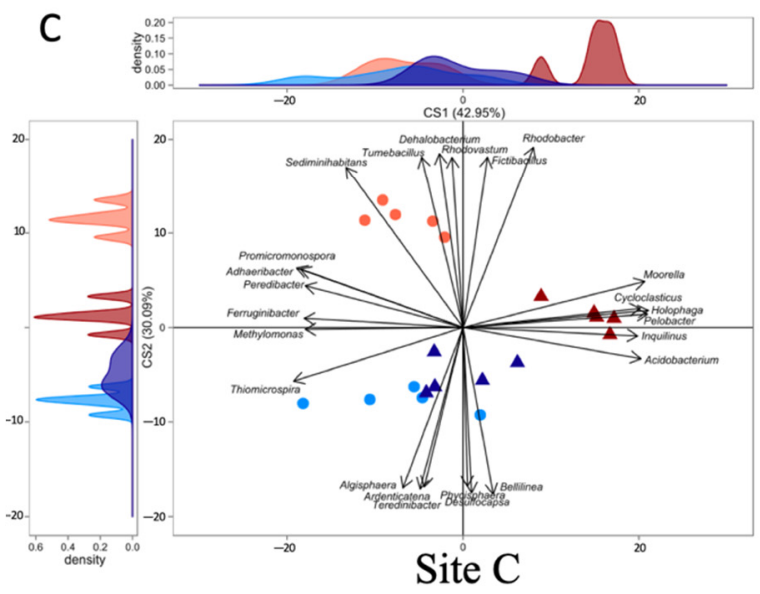

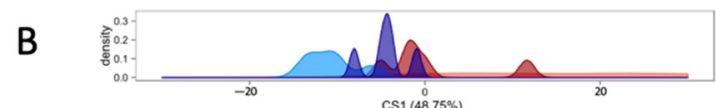

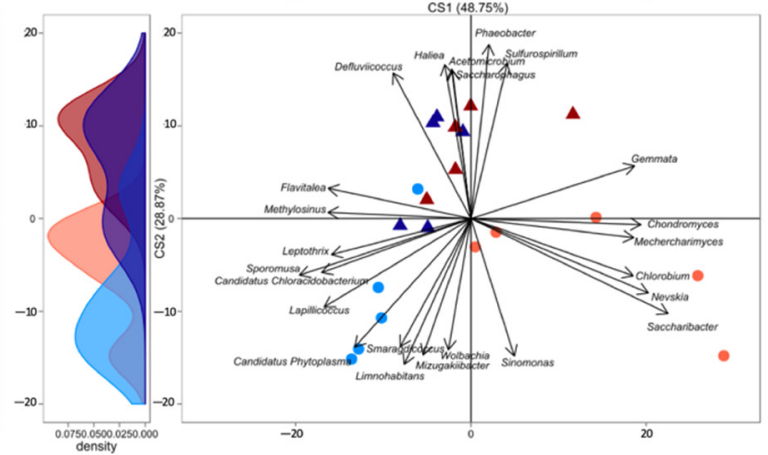

Site FC

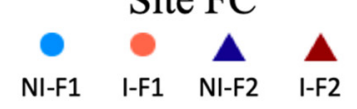

Figure 4. Effect of inoculation level of A. lipoferum CRT1 on the composition of the total bacterial community ( $r r s$ ) as indicated by between-class analyses (BCA) studied at three field sites L (A), FC (B), and C (C). F1 (circles) corresponds to the peat matrix used to coat seeds with low inoculant concentration, using data originating from [21], and in F2 (triangles), A. lipoferum CRT1 was used at higher inoculant concentration. NI (blue) and I (reddish) correspond, respectively, to non-inoculated and inoculated conditions. Curves on top and left represent, respectively, the sample distribution on abscissa and ordinate axes. Vectors on plot represent the bacterial genera contributing the most to sample distribution.

Second, the BCA showed that the effect of inoculation was significant at all three sites with F1, i.e., at site $\mathrm{L}$ along the ordinate axis $\left(p=3.6 \times 10^{-3} ; 33 \%\right.$ of between-class variability), with the most discriminant genera being Candidatus Metachlamydia, Desulfuromusa, Thermoanaerobacter, Jiangella, Tetracoccus and Hydrogenispora (genera most commonly associated with non-inoculated maize), and Desulfopila, Myxococcus, Azonexus, Flavihumibacter, Rhodoferax and Methylophilus (genera most commonly associated with inoculated maize); at site FC along the abscissa axis ( $p=6.9 \times 10^{-3} ; 29 \%$ of between-class variability), with Candidatus Chloracidobacterium, Sporomusa, Lapillicoccus, Methylosinus, Flavitalea and Leptothrix most commonly associated with non-inoculated maize, whereas Saccharibacter, Nevskia, Chondromyces, Gemmata, Mechercharimyces and Chlorobium were genera most commonly associated with inoculated maize; and at site $C$ along the ordinate axis $\left(p=5.5 \times 10^{-3} ; 29 \%\right.$ of between-class variability), with Bellilinea, Desulfocapsa, Ardenticatena, Algisphaera, Teredinibacter and Phycisphaera being most commonly associated with non-inoculated maize, and Rhodobacter, Dehalobacterium, Fictibacillus, Tumebacillus, Rhodovastum and Sediminihabitans most commonly associated with inoculated maize (Figure 4). In contrast, inoculation with 
F2 had no significant effect at sites $\mathrm{L}$ ( $p=0.74$ for axis $\mathrm{X}$ and 0.98 for axis $\mathrm{Y}), \mathrm{FC}$ ( $p=0.83$ for axis $X$ and 0.92 for axis $Y$ ) and $C(p=0.32$ for axis $X$ and 0.47 for axis $Y$ ).

Third, the analysis of taxonomic composition data restricted to the 20 most abundant rhizosphere bacterial genera (Figure S6) did not enable the identification of trends of variations associated with treatment type. However, these genera only accounted for about $40 \%$ of all sequences.

\section{Discussion}

In this work, a reduced formulation F1 providing only $10^{4-5}$ cell equivalents per seed was assessed in comparison with the F2 standard inoculum level of $10^{5-6}$ cell equivalents [34]. This reduced inoculum level did not lead to enhanced maize growth at field FC (unlike the standard formulation F2), but improved growth in the other fields (less than F2 at site C, but to a similar extent at site L). Azospirillum inoculation with the F1 formulation resulted in diminished grain yield at site FC (although it had increased yield in the same field the year before), gave a positive trend (not significant at $p<0.05$ ) with a $16 \%$ yield increase at site $C$, and enhanced yield significantly at site L based on data in Rozier et al. [20]. In comparison, inoculation with the F2 formulation did not improve yield [20], which means that reducing the inoculum level was, in fact, a positive approach in terms of maize phytostimulation.

qPCR assessment of inoculant levels during plant growth in the field showed that the inoculant had failed to survive durably in the rhizosphere [21], which was also found in this work when using the higher F2 inoculum level. This reinforces the concept that A. lipoferum CRT1 acts mainly during the very early stages of maize development, i.e., in the spermosphere $[20,29,35,36]$. Besides enhanced growth, significant effects had been observed under these conditions on photosynthesis, and on leaf and root metabolite contents [20]. A. lipoferum CRT1 was also found, in other maize experiments, to (i) stimulate early root radicle emergence [20,36], (ii) modify the chemical structure of root cell walls, which might improve water retention and resistance to mechanical stress [37], and (iii) affect root and shoot contents of seedlings in phenolic secondary metabolites [38,39].

The quantity of peat-based coating used to associate the inoculated bacteria to the seeds positively affected maize growth. We observed better growth with the non-bacterized F2 control treatment that implicated higher levels of peat-based coating than the F1 control. Soil amendment with peat can influence plant growth parameters and microbiota activities (e.g., cellobiosidase and B-xylosidase activities; [40]), but this was seen with high amounts of peat $\left(300 \mathrm{~m}^{3} \mathrm{ha}^{-1}\right)$. Here, less than $10 \mathrm{dm}^{3}$ of peat was used per ha, so the corresponding nutrient addition was negligible. However, peat contains humic acids [41,42], which may act as auxin-like compounds on maize [43] and might account for root system stimulation. The F2 control treatment also enhanced the abundance of the three studied bacterial functional groups, although enhancement levels were modest.

The main focus of this work was the ecological impact of reduced CRT1 inoculation level on resident rhizosphere bacteria, and more specifically, on key microbial functional groups [21]. The absence of detectable inoculant survival made it unlikely that such an impact would entail strong direct effects of CRT1 cells on neighbouring bacteria colonizing root surfaces, particularly at the reduced inoculation level, but might rather be linked to indirect effects mediated through changes in plant traits [20,36]. Indeed, the BCA of rrs sequences showed that the composition of the rhizobacterial community differed following inoculation with reduced amounts of $A$. lipoferum CRT1 (i.e., with the F1 formulation [21]) at each of the three field sites, but not with the standard CRT1 inoculation $\left(10^{5-6}\right.$ CFU per seed; F2 formulation), pointing to effects of a larger magnitude with the F1 formulation.

Nitrogen fixation and ACC deamination are functions harboured by a minority of taxa $[44,45]$. In the NCBI database, the nifH $H^{+}$bacteria account for only $4.5 \%$ and the $a c d S^{+}$ bacteria for $8.0 \%$ of all available sequenced bacterial genomes $(n=10,369)$. In Orr et al. [46], analyses of microbiota composition revealed that the nifH community accounted for approximatively $2 \%$ of the total community based on qPCR assays in the rhizosphere of barley. 
Sequencing performed in sugarcane [47] and soybean [48] confirmed the small proportion of the diazotroph community. Thus, inoculation effects on these functional communities may not necessarily parallel changes at the level of the total community. Furthermore, the capacity to fix nitrogen (or deaminate ACC) is not shared by all species/strains of a given genus (for a survey see [44]). In Azospirillum, acdS is harboured by A. lipoferum strains 4B and B510, but not by A. lipoferum CRT1, A. baldaniorum (formerly A. brasilense) Sp245 or A. brasilense CBG497 [44]. It should also be noted that host plants may select microorganisms with particular function(s) in the rhizosphere, regardless of the taxa they belong to $[45,47-50]$.

Inoculation effects on the size of rhizosphere bacterial functional groups (when taking place) were of similar magnitude with the two formulations (a 0.2-0.9 log difference). Since inoculation effects on maize growth were more pronounced with F2 (than with F1), one might have expected that F2 inoculation treatments would have led to larger amounts of nutrients exudated by plant roots [51,52] and, in turn, bigger sizes of bacterial functional communities, which was not the case. This suggests that differences in exudate quality might have played a larger role.

Inoculation of $A$. lipoferum CRT1 with formulation F1 or F2 had a field-specific impact on the taxonomic composition of the two functional groups (nifH and acdS), as the effects on both were significant at site FC with formulation F1 vs. sites L and C with formulation F2. FC was the only site where inoculation using formulation F1 resulted in reduced maize growth, therefore suggesting that the impact of F1-formulated CRT1 on these two functional groups was, in this site, a consequence of the direct inoculant effects on maize, rather than a modification contributing to phytostimulation. Indeed, the quantity and quality of root exudates can correlate with root biomass and, more globally, plant development [51-53]. In the two other sites (FC and C), inoculation with formulation F2 showed enhanced impact on root and shoot development when compared with inoculation F1, and this enhanced impact coincided with a modification of the composition of the bacterial functional communities. Distinct effects of CRT1 concentration on the nifH vs. acdS functional groups were evidenced when considering the main genera involved, as these effects were both field- and formulation-specific. It suggests that the ecology of these genera may be governed differently depending on local abiotic and biotic factors, and that the possibility of predicting the impact of inoculation on a given bacterial genus is probably very limited.

In conclusion, this work showed that a thinner formulation providing a lower inoculant level resulted in similar, more pronounced or less pronounced effects on the size of six-leaf plants (depending on field site) although the effects on yield were always more important. Inoculation with A. lipoferum CRT1 affected the size and taxonomic composition of the functional communities involved in nitrogen fixation (nifH) or ACC deamination (acdS), with formulation-specific and field-specific manners. Therefore, our initial hypothesis that reduced inoculum levels should lead to reduced effects on microbial functional groups did not materialize. In addition, only the reduced formulation had a significant impact on the total bacterial community, and thus, further research is needed to decipher the Azospirillum-maize-microbiota interactions underpinning CRT1 phytostimulation.

\section{Materials and Methods}

\subsection{PGPR Strain and Inoculum Preparation}

A. lipoferum CRT1 was isolated from the rhizosphere of maize in a French field [54] and was selected as effective inoculant for maize phytostimulation $[29,35,36,54]$. Inoculum preparation has been described in detail [20]. The maize seeds (Zea mays cv. Seiddi; Caussade Semences, Caussade, France) were inoculated with an industrial coating (Agrauxine Company, Lesaffre Plant Care group, Angers, France) consisting of a proprietary peatbased formulation containing live CRT1 cells [20] to reach a standard inoculation level (F2 formulation) or a reduced inoculation level (formulation F1). The non-inoculated controls consisted of seeds coated under the same conditions and with the exact same peat formula- 
tion (i.e., an F2 control and a thinner F1 control), but without A. lipoferum CRT1. The coated seeds were prepared separately for site $C$ and for sites $\mathrm{L}$ and FC, sown days later.

The inoculum preparation aimed originally at adding $10^{7}$ cells (for F2) and $10^{6}$ cells (for F1) of A. lipoferum CRT1 per seed [20], but the industrial process, and especially the drying phase, lead to subsequent inoculant loss, resulting in $10^{5-6}$ cells.seed $^{-1}$ and $10^{4-5}$ cells.seed $^{-1}$, respectively. Inoculum levels were determined by colony counts on nitrogen-free agar containing ammonium chloride $\left(0.2 \mathrm{~g} \mathrm{~L}^{-1}\right)$ and Congo Red [55], and by quantitative PCR (qPCR) using primers specific for strain CRT1 [34]. At sowing, A. lipoferum CRT1 was recovered from seeds at $3.7 \times 10^{2} \mathrm{CFU}$ (on plates) and $3.0 \times 10^{4}$ cell equivalents (by qPCR) per seed at sites L and FC, and $8.8 \times 10^{2} \mathrm{CFU}$ (on plates) and $1.5 \times 10^{5}$ cell equivalents (by qPCR) per seed at site $C$ for formulation F1. With formulation F2, A. lipoferum CRT1 was at $1.7 \times 10^{3} \mathrm{CFU}$ (on plates) and $3.8 \times 10^{5}$ cell equivalents (by qPCR) per seed at sites $\mathrm{L}$ and FC, and $1.2 \times 10^{4} \mathrm{CFU}$ (on plates) and $1.2 \times 10^{6}$ cell equivalents (by qPCR) per seed at site $C$.

\subsection{Field Trials and Treatments}

The field trials were run in 2015 in Chatonnay (site L), Sérézin-de-la-Tour (site FC) and Saint Savin (site C), which are located in the vicinity of Bourgoin-Jallieu (Isère, France). Details can be found in Rozier et al. [20]. The soils are classified (FAO system) as cambisol (C), luvisol (L) and fluvic-cambisol (FC), respectively. Each site grew wheat in 2013 and maize in 2014. The coated maize seeds were sown on April 30 (at C) and May 11 (at FC and L).

Each field experiment followed a factorial design with four combinations of factors, i.e., inoculation $($ A lipoferum CRT1 or no inoculation) $\times$ formulation (standard formulation F2 or reduced formulation F1), and five randomised replicate blocks. The individual replicate plots ( 5 per treatment combination) were 12 rows (at FC and C) or 8 rows wide (at L) and $12 \mathrm{~m}$ long, and did not receive mineral nitrogen fertilizer.

\subsection{Sampling of Maize}

The maize was sampled at the six-leaf stage, on 27 May (C), 5 June (FC) and 8 June (L), as well as at the flowering stage, on 15 I, 16 (FC) and 17 (L) July. At each sampling, four root systems were taken per plot, i.e., 20 samples per treatment condition.

Upon uprooting, each root system was shaken to dislodge loosely adhering soil and flash-frozen in liquid nitrogen, followed by lyophilisation $\left(24 \mathrm{~h}\right.$ at $\left.-50{ }^{\circ} \mathrm{C}\right)$ in the laboratory. The root-adhering soil (i.e., rhizosphere soil) was separated from the roots using brushes and stored at $-80^{\circ} \mathrm{C}$, prior to DNA extraction using the FastDNA SPIN kit (BIO 101 Inc., Carlsbad, CA, USA). The DNA samples (300 mg) were transferred to Lysing Matrix E tubes, along with $5 \mu \mathrm{L}$ of the internal standard APA9 (at $10^{9}$ copies $\mathrm{mL}^{-1}$ ), in order to normalize the efficiency of the DNA extraction between the rhizosphere soil samples [34,56]. APA9 is vector pUC19 containing a cassava virus insert (GenBank accession number AJ427910), and was amplified with primers AV1f/AV1r, as described [34]. After a $1 \mathrm{~h}$ incubation at $4{ }^{\circ} \mathrm{C}$, DNA was extracted and eluted in $50 \mathrm{~mL}$ sterile ultra-pure water, according to the manufacturer's instructions, and DNA concentrations were assessed using Picogreen (ThermoFisher, Waltham, MA, USA).

\subsection{Plant Growth Monitoring}

Nine plant development parameters were measured on five six-leaves stage plants per plot (25 plants per treatment). The monitoring of root development was based on root dry biomass and root system architecture via the quantification of total root length, surface, and number, as well as average root diameter (WinRHIZO; Regent Instruments Inc., Québec City, Canada). The monitoring of shoot development was based on shoot dry biomass and stem diameter at the root collar, and on foliar morphology via the quantification of the length and average width of the fifth leaf from the shoot bottom (WinFOLIA; Regent Instruments Inc.). Data obtained with formulation F2 have been reported by [20,21]. 


\subsection{Quantitative PCR Analysis of Microbial Functional Groups}

The copy number of genes nifH, acdS and phlD in the maize rhizosphere was assessed by quantitative PCR using, respectively, (i) primers polF/polR [57] advocated for combined quantitative PCR and diversity analyses [45,58], (ii) primers acdSF5/acdSR8 validated for analysis of true $a c d S$ genes (i.e., without amplifying related D-cystein desulfhydrase genes coding for other types of PLP-dependent enzymes; [45,50]), and (iii) primers B2BF/B2BR3 [59]. Briefly, the reaction for nifH or acdS was performed in $20 \mu \mathrm{L}$ containing $4 \mu \mathrm{L}$ of PCR-grade water, $1 \mu \mathrm{L}$ of each primer (final concentration $0.50 \mu \mathrm{M}$ ), $10 \mu \mathrm{L}$ of LightCycler-DNA Master SYBR Green I master mix (Roche Applied Science, Meylan, France) and $2 \mu \mathrm{L}$ of sample DNA (5 ng) [45]. The reaction for phlD was carried out in $20 \mu \mathrm{L}$ containing $1.9 \mu \mathrm{L}$ of PCR grade water, $1 \mu \mathrm{L}$ of each primer (final concentration $1 \mu \mathrm{M}$ ), $10 \mu \mathrm{L}$ of LightCycler-DNA Master SYBR Green I master mix (Roche Applied Science), $0.5 \mathrm{mg}$ of T4g32 protein, $3 \%$ DMSO, and $2 \mu \mathrm{L}$ of sample DNA (10 ng). PCR was performed for $10 \mathrm{~min}$ at $95^{\circ} \mathrm{C}$, followed by 50 cycles of: (i) $95^{\circ} \mathrm{C}$ for $15 \mathrm{~s}$ (nifH), $94{ }^{\circ} \mathrm{C}$ for $15 \mathrm{~s}$ (acdS), or $94{ }^{\circ} \mathrm{C}$ for $30 \mathrm{~s}\left(\right.$ phlD); (ii) $64^{\circ} \mathrm{C}$ for $15 \mathrm{~s}$ (nifH), $67^{\circ} \mathrm{C}$ for $15 \mathrm{~s}$ (acdS), or $67^{\circ} \mathrm{C}$ for $7 \mathrm{~s}$ (phlD); and (iii) $72{ }^{\circ} \mathrm{C}$ for $10 \mathrm{~s} \mathrm{(nifH} \mathrm{and} a c d S$ ) or $15 \mathrm{~s}$ (phlD). A melting curve calculation and Tm determination were carried out using the Tm Calling Analysis module of Light-Cycler Software v.1.5 (Roche Applied Science). Real-time PCR quantification data were converted to gene copy number per gram of lyophilized root-adhering soil, as performed by [60]. Data obtained with formulation F1 have been shown [21].

\subsection{Metabarcoding of rrs (Bacterial Community), nifH (Diazotrophs) and acdS (ACC Deaminase Producers)}

Sequencing was carried out for samples from six-leaf maize. Equimolar composite samples of four rhizosphere DNA extracts (from four plants) were analysed per plot, i.e., 5 plots $\times 3$ fields $=15$ samples per treatment. Illumina MiSeq sequencing $(2 \times 300 \mathrm{bp}$ for nifH and $r r s ; 2 \times 125 \mathrm{bp}$ for $a c d S$ ) was performed by MR DNA laboratory (www.mrdnalab. com (accessed on 31 December 2021); Shallowater, TX, USA).

nifH and acdS sequencings were conducted using the same primers, polF/polR and acdSF5/acdSR8, respectively, whereas sequencing of the 16S rRNA gene $r r s$ was conducted with primers 515/806 for the $\mathrm{V} 4$ variable region [61]. All forward primers carried a barcode. The 30-cycle PCR (5 cycles implemented on PCR products) was performed using the HotStarTaq Plus Master Mix Kit (Qiagen, Valencia, CA) with the following conditions: $94{ }^{\circ} \mathrm{C}$ for $3 \mathrm{~min}$, followed by 28 cycles of $94^{\circ} \mathrm{C}$ for $30 \mathrm{~s}, 53^{\circ} \mathrm{C}$ for $40 \mathrm{~s}$ and $72{ }^{\circ} \mathrm{C}$ for $1 \mathrm{~min}$, and a final elongation step at $72{ }^{\circ} \mathrm{C}$ for $5 \mathrm{~min}$. The PCR products were checked in $2 \%$ agarose gel to verify the amplification success and relative band intensity. Multiple samples were pooled together in equal proportions based on their molecular weight and DNA concentrations. The pooled samples were purified using calibrated Ampure XP beads prior to preparing a DNA library following Illumina TruSeq DNA library preparation protocol. The reads have been deposited in the European Bioinformatics Institute (EBI) database under accession numbers PRJEB14346 (nifH), PRJEB14343 (acdS), PRJEB14347 (rrs).

The sequence data were processed using the analysis pipeline of MR DNA. Briefly, sequences were depleted of barcodes, the sequences $<150 \mathrm{bp}$ or with ambiguous base calls were removed, the remaining sequences denoised, the operational taxonomic units (OTUs; defined at 3\% divergence threshold for the three genes) generated, and the chimeras and singletons removed. Final the OTUs were taxonomically classified using BLASTn against a curated database derived from Greengenes [62], RDPII (http:/ / rdp.cme.msu.edu) and NCBI (www.ncbi.nlm.nih.gov (accessed on 31 December 2021)). Final OTUs of the acdS sequencing were classified using an in-house curated acdS database [50].

nifH sequencing of six-leaf maize rhizosphere soil in 2015 gave 1,342,966 sequences (10,775 to 62,752 sequences per sample), corresponding to 36,241 OTUs. acdS sequencing resulted in 5,490,230 sequences (68,376 to 139,245 per sample), which yielded 32,468 OTUs. rrs sequencing was also performed to determine whether inoculation effects could also take place at the scale of the rhizobacterial community. A total of 6,082,255 reads were 
obtained (51,696 to 223,926 per sample), corresponding to 39,600 OTUs. For all three genes, rarefaction analysis indicated that the curves reached a plateau (Figures S1-S3). The relative abundance of bacterial genera identified following the analysis of nifH, acdS and rrs sequence reads is shown in Figures S4, S5 and S6, respectively. Data obtained with formulation F1 are shown in [21].

\subsection{Statistical Analyses}

The plant data and log-transformed quantitative PCR data were compared by onefactor ANOVA and Fishers' LSD tests, or Kruskal-Wallis rank sum tests when data were non-parametric. The comparisons for bacterial composition data were carried out by Between-Class Analysis (BCA) [63,64], using ADE4 and ggplot2 packages for R (https: / / www.r-project.org / 31 December 2021), and the Kruskal-Wallis rank sum tests associated to Tukey's HSD tests. Non-metric multidimensional scaling (NMDS) was also performed, using the Bray-Curtis distance and the vegan package for R. The genus composition of the bacterial community and functional groups were characterized to consider the relative abundance of the most prevalent taxa. Statistical analyses were performed at $p<0.05$, using R v3.1.2 (R Core Team [65]).

Supplementary Materials: The following supporting information can be downloaded at: https: / / www.mdpi.com/article/10.3390/microorganisms10020325/s1, Figure S1: Rarefaction curves for rrs at field sites L, FC and C. NI and I correspond, respectively, to non-inoculated and inoculated conditions. F1 and F2 correspond, respectively, to $10^{4-5}$ (reduced) and $10^{5-6}$ (standard) cells.seed ${ }^{-1}$ of the seed inoculant $A$. lipoferum CRT1. Data obtained with formulation F1 have already been shown in [21]; Figure S2: Rarefaction curves for $a c d S$ at field sites L, FC and C. NI and I correspond, respectively, to non-inoculated and inoculated conditions. F1 and F2 correspond, respectively, to $10^{4-5}$ (reduced) and $10^{5-6}$ (standard) cells.seed ${ }^{-1}$ of the seed inoculant $A$. lipoferum CRT1. Data obtained with formulation F1 have already been shown in [21]; Figure S3: Rarefaction curves for nifH at field sites L, FC and C. NI and I correspond respectively to non-inoculated and inoculated conditions. F1 and F2 correspond, respectively, to $10^{4-5}$ (reduced) and $10^{5-6}$ (standard) cells.seed ${ }^{-1}$ of the seed inoculant A. lipoferum CRT1. Data obtained with formulation F1 have already been shown in [21]; Figure S4: Relative abundance of bacterial genera based on analysis of nifH data pooled for field sites L, FC and C. NI and I correspond, respectively, to non-inoculated and inoculated conditions. F1 and F2 correspond, respectively, to $10^{4-5}$ (reduced) and $10^{5-6}$ (standard) cells.seed ${ }^{-1}$ of the seed inoculant A. lipoferum CRT1. Data obtained with formulation F1 have already been shown in [21]; Figure S5: Relative abundance of bacterial genera based on analysis of acdS data pooled for field sites L, FC and C. NI and I correspond, respectively, to non-inoculated and inoculated conditions. F1 and F2 correspond, respectively, to $10^{4-5}$ (reduced) and $10^{5-6}$ (standard) cells.seed ${ }^{-1}$ of the seed inoculant A. lipoferum CRT1. Data obtained with formulation F1 have already been shown in [21]; Figure S6: Relative abundance of bacterial genera based on analysis of $r r s$ data pooled for field sites L, FC and C. NI and I correspond, respectively, to non-inoculated and inoculated conditions. F1 and F2 correspond, respectively, to $10^{4-5}$ (reduced) and $10^{5-6}$ (standard) cells.seed ${ }^{-1}$ of the seed inoculant A. lipoferum CRT1. Data obtained with formulation F1 have already been shown in [21]; Figure S7: Non-metric multidimensional scaling (NMDS) of $r r s$ data at all three field sites L (Chatonnay), FC (Sérézin-de-la-Tour) and C (Saint Savin) (A), at field site L only (B), at field site FC only (C), and at field site C only (D). NI and I correspond, respectively, to non-inoculated and inoculated conditions. F1 and F2 correspond, respectively, to $10^{4-5}$ (reduced) and $10^{5-6}$ (standard) cells.seed ${ }^{-1}$ of the seed inoculant $A$. lipoferum CRT1. NMDS of distance matrices was based on the Bray-Curtis distance and was done using the vegan package in R; Figure S8: Non-metric multidimensional scaling (NMDS) of nifH data at all three field sites L (Chatonnay), FC (Sérézin-de-la-Tour) and C (Saint Savin) (A), at field site L only (B), at field site FC only (C), and at field site C only (D). NI and I correspond, respectively, to non-inoculated and inoculated conditions. F1 and F2 correspond, respectively, to $10^{4-5}$ (reduced) and $10^{5-6}$ (standard) cells.seed ${ }^{-1}$ of the seed inoculant $A$. lipoferum CRT1. NMDS of distance matrices was based on the Bray-Curtis distance and was done using the vegan package in R; Figure S9: Non-metric multidimensional scaling (NMDS) of acdS data at all three field sites L (Chatonnay), FC (Sérézin-la-Tour) and C (Saint Savin) (A), at field site L only (B), at field site FC only (C), and at field site C only (D). NI and I correspond, respectively, to non-inoculated and inoculated 
conditions. F1 and F2 correspond, respectively, to $10^{4-5}$ (reduced) and $10^{5-6}$ (standard) cells.seed ${ }^{-1}$ of the seed inoculant $A$. lipoferum CRT1. NMDS of distance matrices was based on the Bray-Curtis distance and was done using the vegan package in $\mathrm{R}$.

Author Contributions: Y.M.-L., L.L. and D.M. designed the project; S.R., C.P.-C., F.W.-D., L.L., Y.M.-L. and D.M. carried out field work; S.R. conducted the molecular work; S.R. and D.A. implemented bioinformatic analyses; S.R., Y.M.-L. and D.M. analysed the data; S.R., Y.M.-L. and D.M. prepared the first draft of the manuscript, which was finalized by all authors. All authors have read and agreed to the published version of the manuscript.

Funding: This research was funded by ANR projects Azodure (ANR-12-AGRO-0008) and Deep Impact (ANR-20-PCPA-0004).

Institutional Review Board Statement: Not applicable.

Informed Consent Statement: Not applicable.

Data Availability Statement: Reads have been deposited in the European Bioinformatics Institute (EBI) database under accession numbers PRJEB14346 (nifH), PRJEB14343 (acdS), PRJEB14347 (rrs).

Acknowledgments: We are grateful to J. Haurat and H. Brunet for their technical help, farmers J.L. Varnet (Saint Savin), Y. Ripet (Sérézin-de-la-Tour) and H. Michon (Chatonnay) for access to their fields, Agrauxine for the inoculant products, and La Dauphinoise coop for the field management.

Conflicts of Interest: The authors declare no conflict of interest. The funders had no role in the design of the study; in the collection, analyses, or interpretation of data; in the writing of the manuscript, or in the decision to publish the results.

\section{References}

1. Date, R.A. Advances in inoculant technology: A brief review. Aust. J. Exp. Agric. 2001, 41, 321-325. [CrossRef]

2. Bashan, Y.; de-Bashan, L.E.; Prabhu, S.R.; Hernandez, J.-P. Advances in plant growth-promoting bacterial inoculant technology: Formulations and practical perspectives (1998-2013). Plant Soil 2014, 378, 1-33. [CrossRef]

3. Bruto, M.; Prigent-Combaret, C.; Luis, P.; Hoff, G.; Moënne-Loccoz, Y.; Muller, D. Horizontal Acquisition of Prokaryotic Genes for Eukaryote Functioning and Niche Adaptation. In Evolutionary Biology: Exobiology and Evolutionary Mechanisms; Pontarotti, P., Ed.; Springer: Berlin/Heidelberg, Germany, 2013; pp. 165-179.

4. Karadeniz, A.; Topcuoğlu, S.; Inan, S. Auxin, gibberellin, cytokinin and abscisic acid production in some bacteria. World J. Microbiol. Biotechnol. 2006, 22, 1061-1064. [CrossRef]

5. Richardson, A.; Baréa, J.; McNeill, A.; Prigent-Combaret, C. Acquisition of phosphorus and nitrogen in the rhizosphere and plant growth promotion by microorganisms. Plant Soil 2009, 321, 305-339. [CrossRef]

6. Glick, B.R. Plant growth-promoting bacteria: Mechanisms and applications. Scientifica 2012, 2012, 963401. [CrossRef]

7. Vacheron, J.; Desbrosses, G.; Bouffaud, M.-L.; Touraine, B.; Moënne-Loccoz, Y.; Muller, D.; Legendre, L.; Wisniewski-Dyé, F.; Prigent-Combaret, C. Plant growth-promoting rhizobacteria and root system functioning. Front. Plant Sci. 2013, 4, 356. [CrossRef]

8. Pii, Y.; Mimmo, T.; Tomasi, N.; Terzano, R.; Cesco, S.; Crecchio, C. Microbial interactions in the rhizosphere: Beneficial influences of plant growth-promoting rhizobacteria on nutrient acquisition process. A review. Biol. Fertil. Soils 2015, 51, 403-415. [CrossRef]

9. Okon, Y.; Labandera-Gonzalez, C.A. Agronomic applications of Azospirillum: An evaluation of 20 years worldwide field inoculation. Soil Biol. Biochem. 1994, 26, 1591-1601. [CrossRef]

10. Cassán, F.; Diaz-Zorita, M. Azospirillum sp. in current agriculture: From the laboratory to the field. Soil Biol. Biochem. 2016, 103, 117-130. [CrossRef]

11. Nephali, L.; Moodley, V.; Piater, L.; Steenkamp, P.; Buthelezi, N.; Dubery, I.; Burgess, K.; Huyser, J.; Tugizimana, F. A metabolomic landscape of maize plants treated with a microbial biostimulant under well-watered and drought conditions. Front. Plant Sci. 2021, 12, 977. [CrossRef]

12. Castro-Sowinski, S.; Herschkovitz, Y.; Okon, Y.; Jurkevitch, E. Effects of inoculation with plant growth-promoting rhizobacteria on resident rhizosphere microorganisms. FEMS Microbiol. Lett. 2007, 276, 1-11. [CrossRef] [PubMed]

13. Gerhardson, B. Biological substitutes for pesticides. Trends Biotechnol. 2002, 20, 338-343. [CrossRef]

14. Eisenhauer, N.; Cesarz, S.; Koller, R.; Worm, K.; Reich, P.B. Global change belowground: Impacts of elevated $\mathrm{CO}_{2}$, nitrogen, and summer drought on soil food webs and biodiversity. Glob. Chang. Biol. 2012, 18, 435-447. [CrossRef]

15. Reynolds, M.P.; Quilligan, E.; Aggarwal, P.K.; Bansal, K.C.; Cavalieri, A.J.; Chapman, S.C.; Chapotin, S.M.; Datta, S.K.; Duveiller, E.; Gill, K.S.; et al. An integrated approach to maintaining cereal productivity under climate change. Glob. Food Secur. 2016, 8 , 9-18. [CrossRef]

16. Backer, R.; Rokem, J.S.; Ilangumaran, G.; Lamont, J.; Praslickova, D.; Ricci, E.; Subramanian, S.; Smith, D.L. Plant growthpromoting rhizobacteria: Context, mechanisms of action, and roadmap to commercialization of biostimulants for sustainable agriculture. Front. Plant Sci. 2018, 9, 1473. [CrossRef] [PubMed] 
17. Martínez-Viveros, O.; Jorquera, M.A.; Crowley, D.E.; Gajardo, G.; Mora, M.L. Mechanisms and practical considerations involved in plant growth promotion by rhizobacteria. J. Soil Sci. Plant Nutr. 2010, 10, 293-319. [CrossRef]

18. Veresoglou, S.D.; Menexes, G. Impact of inoculation with Azospirillum spp. on growth properties and seed yield of wheat: A meta-analysis of studies in the ISI Web of Science from 1981 to 2008. Plant Soil 2010, 337, 469-480. [CrossRef]

19. Souza, R.; Ambrosini, A.; Passaglia, L.M. Plant growth-promoting bacteria as inoculants in agricultural soils. Genet. Mol. Biol. 2015, 38, 401-419. [CrossRef]

20. Rozier, C.; Hamzaoui, J.; Lemoine, D.; Czarnes, S.; Legendre, L. Field-based assessment of the mechanism of maize yield enhancement by Azospirillum lipoferum CRT1. Sci. Rep. 2017, 7, 7416. [CrossRef]

21. Renoud, S.; Vacheron, J.; Abrouk, D.; Prigent-Combaret, C.; Legendre, L.; Muller, D.; Moënne-Loccoz, Y. Field site-specific effects of an Azospirillum seed inoculant on key microbial functional groups in the rhizosphere. Front. Microbiol. 2022, $12,760512$. [CrossRef]

22. Nakkeeran, S.; Fernando, W.G.D.; Siddiqui, Z.A. Plant Growth Promoting Rhizobacteria Formulations and its Scope in Commercialization for the Management of Pests and Diseases. In PGPR: Biocontrol and Biofertilization; Siddiqui, Z.A., Ed.; Springer: Dordrecht, The Netherlands, 2005; Volume 1, pp. 257-296.

23. Bashan, Y. Inoculants of plant growth-promoting bacteria for use in agriculture. Biotechnol. Adv. 1998, 16, 729-770. [CrossRef]

24. Bashan, Y. Significance of timing and level of inoculation with rhizosphere bacteria on wheat plants. Soil Biol. Biochem. 1986, 18, 297-301. [CrossRef]

25. Catroux, G.; Hartmann, A.; Revellin, C. Trends in rhizobial inoculant production and use. Plant Soil 2001, 230, 21-30. [CrossRef]

26. Hume, D.J.; Blair, D.H. Effect of numbers of Bradyrhizobium japonicum applied in commercial inoculants on soybean seed yield in Ontario. Can. J. Microbiol. 1992, 38, 588-593. [CrossRef]

27. Pillay, V.K.; Nowak, J. Inoculum density, temperature, and genotype effects on in vitro growth promotion and epiphytic and endophytic colonization of tomato (Lycopersicon esculentum L.) seedlings inoculated with a pseudomonad bacterium. Can. J. Microbiol. 1997, 43, 354-361. [CrossRef]

28. Bai, Y.; Pan, B.; Charles, T.C.; Smith, D.L. Co-inoculation dose and root zone temperature for plant growth promoting rhizobacteria on soybean [Glycine max (L.) Merr] grown in soil-less media. Soil Biol. Biochem. 2002, 34, 1953-1957. [CrossRef]

29. Jacoud, C.; Job, D.; Wadoux, P.; Bally, R. Initiation of root growth stimulation by Azospirillum lipoferum CRT1 during maize seed germination. Can. J. Microbiol. 1999, 45, 339-342. [CrossRef]

30. El Zemrany, H.; Cortet, J.; Peter Lutz, M.; Chabert, A.; Baudoin, E.; Haurat, J.; Maughan, N.; Félix, D.; Défago, G.; Bally, R.; et al. Field survival of the phytostimulator Azospirillum lipoferum CRT1 and functional impact on maize crop, biodegradation of crop residues, and soil faunal indicators in a context of decreasing nitrogen fertilisation. Soil Biol. Biochem. 2006, 38, 1712-1726. [CrossRef]

31. Florio, A.; Pommier, T.; Gervaix, J.; Bérard, A.; Le Roux, X. Soil C and N statuses determine the effect of maize inoculation by plant growth-promoting rhizobacteria on nitrifying and denitrifying communities. Sci. Rep. 2017, 7, 8411. [CrossRef]

32. Baudoin, E.; Nazaret, S.; Mougel, C.; Ranjard, L.; Moënne-Loccoz, Y. Impact of inoculation with the phytostimulatory PGPR Azospirillum lipoferum CRT1 on the genetic structure of the rhizobacterial community of field-grown maize. Soil Biol. Biochem. 2009, 41, 409-413. [CrossRef]

33. Brazelton, J.N.; Pfeufer, E.E.; Sweat, T.A.; McSpadden Gardener, B.B.; Coenen, C. 2,4-diacetylphloroglucinol alters plant root development. Mol. Plant-Microbe Interact. 2008, 21, 1349-1358. [CrossRef] [PubMed]

34. Couillerot, O.; Bouffaud, M.-L.; Baudoin, E.; Muller, D.; Caballero-Mellado, J.; Moënne-Loccoz, Y. Development of a real-time PCR method to quantify the PGPR strain Azospirillum lipoferum CRT1 on maize seedlings. Soil Biol. Biochem. 2010, 42, $2298-2305$. [CrossRef]

35. Jacoud, C.; Faure, D.; Wadoux, P.; Bally, R. Development of a strain-specific probe to follow inoculated Azospirillum lipoferum CRT1 under field conditions and enhancement of maize root development by inoculation. FEMS Microbiol. Ecol. 1998, $27,43-51$. [CrossRef]

36. Rozier, C.; Gerin, F.; Czarnes, S.; Legendre, L. Biopriming of maize germination by the plant growth-promoting rhizobacterium Azospirillum lipoferum CRT1. J. Plant Physiol. 2019, 237, 111-119. [CrossRef]

37. El Zemrany, H.; Czarnes, S.; Hallett, P.D.; Alamercery, S.; Bally, R.; Jocteur Monrozier, L. Early changes in root characteristics of maize (Zea mays) following seed inoculation with the PGPR Azospirillum lipoferum CRT1. Plant Soil 2007, 291, 109-118. [CrossRef]

38. Walker, V.; Bertrand, C.; Bellvert, F.; Moënne-Loccoz, Y.; Bally, R.; Comte, G. Host plant secondary metabolite profiling shows a complex, strain-dependent response of maize to plant growth-promoting rhizobacteria of the genus Azospirillum. New Phytol. 2011, 189, 494-506. [CrossRef]

39. Walker, V.; Couillerot, O.; Von Felten, A.; Bellvert, F.; Jansa, J.; Maurhofer, M.; Bally, R.; Moënne-Loccoz, Y.; Comte, G. Variation of secondary metabolite levels in maize seedling roots induced by inoculation with Azospirillum, Pseudomonas and Glomus consortium under field conditions. Plant Soil 2012, 356, 151-163. [CrossRef]

40. Vepsäläinen, M.; Erkomaa, K.; Kukkonen, S.; Vestberg, M.; Wallenius, K.; Niemi, R.M. The impact of crop plant cultivation and peat amendment on soil microbial activity and structure. Plant Soil 2004, 264, 273-286. [CrossRef]

41. Rice, J.A.; MacCarthy, P. Statistical evaluation of the elemental composition of humic substances. Org. Geochem. 1991, 17, 635-648. [CrossRef]

42. Klavins, M.; Purmalis, O. Properties and structure of raised bog peat humic acids. J. Mol. Struct. 2013, 1050, 103-113. [CrossRef] 
43. Eyheraguibel, B.; Silvestre, J.; Morard, P. Effects of humic substances derived from organic waste enhancement on the growth and mineral nutrition of maize. Bioresour. Technol. 2008, 99, 4206-4212. [CrossRef] [PubMed]

44. Bruto, M.; Prigent-Combaret, C.; Muller, D.; Moënne-Loccoz, Y. Analysis of genes contributing to plant-beneficial functions in plant growth-promoting rhizobacteria and related Proteobacteria. Sci. Rep. 2014, 4, 6261. [CrossRef] [PubMed]

45. Renoud, S.; Bouffaud, M.L.; Dubost, A.; Prigent-Combaret, C.; Legendre, L.; Moënne-Loccoz, Y.; Muller, D. Co-occurrence of rhizobacteria with nitrogen fixation and/or 1-aminocyclopropane-1-carboxylate deamination abilities in the maize rhizosphere. FEMS Microbiol. Ecol. 2020, 96, fiaa062. [CrossRef] [PubMed]

46. Orr, C.H.; James, A.; Leifert, C.; Cooper, J.M.; Cummings, S.P. Diversity and activity of free-living nitrogen-fixing bacteria and total bacteria in organic and conventionally managed soils. Appl. Environ. Microbiol. 2011, 77, 911-919. [CrossRef]

47. Yeoh, Y.K.; Paungfoo-Lonhienne, C.; Dennis, P.G.; Robinson, N.; Ragan, M.A.; Schmidt, S.; Hugenholtz, P. The core root microbiome of sugarcanes cultivated under varying nitrogen fertilizer application. Environ. Microbiol. 2016, 18, $1338-1351$. [CrossRef]

48. Mendes, L.W.; Kuramae, E.E.; Navarrete, A.A.; van Veen, J.A.; Tsai, S.M. Taxonomical and functional microbial community selection in soybean rhizosphere. ISME J. 2014, 8, 1577-1587. [CrossRef]

49. Köberl, M.; Erlacher, A.; Ramadan, E.M.; El-Arabi, T.F.; Müller, H.; Bragina, A.; Berg, G. Comparisons of diazotrophic communities in native and agricultural desert ecosystems reveal plants as important drivers in diversity. FEMS Microbiol. Ecol. 2015, 92 , fiv166. [CrossRef]

50. Bouffaud, M.-L.; Renoud, S.; Dubost, A.; Moënne-Loccoz, Y.; Muller, D. 1-Aminocyclopropane-1-carboxylate deaminase producers associated to maize and other Poaceae species. Microbiome 2018, 6, 114. [CrossRef]

51. Amos, B.; Walters, D.T. Maize root biomass and net rhizodeposited carbon. Soil Sci. Soc. Am. J. 2006, 70, 1489-1503. [CrossRef]

52. Murphy, M.T.; Moore, T.R. Linking root production to aboveground plant characteristics and water table in a temperate bog. Plant Soil 2010, 336, 219-231. [CrossRef]

53. Aulakh, M.; Wassmann, R.; Bueno, C.; Kreuzwieser, J.; Rennenberg, H. Characterization of root exudates at different growth stages of ten rice (Oryza sativa L.) cultivars. Plant Biol. 2001, 3, 139-148. [CrossRef]

54. Fages, J.; Mulard, D. Isolement de bactéries rhizosphériques et effet de leur inoculation en pots chez Zea mays. Agronomie 1988, 8 , 309-314. [CrossRef]

55. Cáceres, E.A. Improved medium for isolation of Azospirillum spp. Appl. Environ. Microbiol. 1982, 44, 990-991. [CrossRef] [PubMed]

56. Park, J.-W.; Crowley, D.E. Normalization of soil DNA extraction for accurate quantification of target genes by real-time PCR and DGGE. Biotechniques 2005, 38, 579-586. [CrossRef]

57. Poly, F.; Jocteur Monrozier, L.; Bally, R. Improvement in the RFLP procedure for studying the diversity of nifH genes in communities of nitrogen fixers in soil. Res. Microbiol. 2001, 152, 95-103. [CrossRef]

58. Bouffaud, M.-L.; Renoud, S.; Moënne-Loccoz, Y.; Muller, D. Is plant evolutionary history impacting recruitment of diazotrophs and nifH expression in the rhizosphere? Sci. Rep. 2016, 6, 21690. [CrossRef]

59. Almario, J.; Moënne-Loccoz, Y.; Muller, D. Monitoring of the relation between 2,4-diacetylphloroglucinol-producing Pseudomonas and Thielaviopsis basicola populations by real-time PCR in tobacco black root-rot suppressive and conducive soils. Soil Biol. Biochem. 2013, 57, 144-155. [CrossRef]

60. Couillerot, O.; Ramírez-Trujillo, A.; Walker, V.; von Felten, A.; Jansa, J.; Maurhofer, M.; Défago, G.; Prigent-Combaret, C.; Comte, G.; Caballero-Mellado, J.; et al. Comparison of prominent Azospirillum strains in Azospirillum-Pseudomonas-Glomus consortia for promotion of maize growth. Appl. Microbiol. Biotechnol. 2013, 97, 4639-4649. [CrossRef]

61. Yang, B.; Wang, Y.; Qian, P.-Y. Sensitivity and correlation of hypervariable regions in 16S rRNA genes in phylogenetic analysis. BMC Bioinform. 2016, 17, 135. [CrossRef]

62. DeSantis, T.Z.; Hugenholtz, P.; Larsen, N.; Rojas, M.; Brodie, E.L.; Keller, K.; Huber, T.; Dalevi, D.; Hu, P.; Andersen, G.L. Greengenes, a chimera-checked $16 \mathrm{~S}$ rRNA genedatabase and workbench compatible with ARB. Appl. Environ. Microbiol. 2006, 72, 5069-5072. [CrossRef]

63. Dolédec, S.; Chessel, D. Rythmes saisonniers et composantes stationnelles en milieu aquatique. I: Description d'un plan d'observations complet par projection de variables. Acta Oecol. Oecol. Gen. 1987, 8, 403-426.

64. Thioulouse, J.; Prin, Y.; Duponnois, R. Multivariate analyses in soil microbial ecology: A new paradigm. Environ. Ecol. Stat. 2012, 19, 499-520. [CrossRef]

65. R Core Team. R: A Language and Environment for Statistical Computing; R Foundation for Statistical Computing: Vienna, Austria, 2013. 